\title{
Route-Based Control of Hybrid Electric Vehicles
}

Conference Paper NREL/CP-540-42557 January 2008

\section{Preprint}

\author{
J.D. Gonder
}

To be presented at SAE 2008 World Congress Detroit, Michigan

April 14-17, 2008 


\section{NOTICE}

The submitted manuscript has been offered by an employee of the Midwest Research Institute (MRI), a contractor of the US Government under Contract No. DE-AC36-99G010337. Accordingly, the US Government and MRI retain a nonexclusive royalty-free license to publish or reproduce the published form of this contribution, or allow others to do so, for US Government purposes.

This report was prepared as an account of work sponsored by an agency of the United States government. Neither the United States government nor any agency thereof, nor any of their employees, makes any warranty, express or implied, or assumes any legal liability or responsibility for the accuracy, completeness, or usefulness of any information, apparatus, product, or process disclosed, or represents that its use would not infringe privately owned rights. Reference herein to any specific commercial product, process, or service by trade name, trademark, manufacturer, or otherwise does not necessarily constitute or imply its endorsement, recommendation, or favoring by the United States government or any agency thereof. The views and opinions of authors expressed herein do not necessarily state or reflect those of the United States government or any agency thereof.

Available electronically at http://www.osti.gov/bridge

Available for a processing fee to U.S. Department of Energy and its contractors, in paper, from:

U.S. Department of Energy

Office of Scientific and Technical Information

P.O. Box 62

Oak Ridge, TN 37831-0062

phone: 865.576 .8401

fax: 865.576 .5728

email: mailto:reports@adonis.osti.gov

Available for sale to the public, in paper, from:

U.S. Department of Commerce

National Technical Information Service

5285 Port Royal Road

Springfield, VA 22161

phone: 800.553 .6847

fax: 703.605.6900

email: orders@ntis.fedworld.gov

online ordering: http://www.ntis.gov/ordering.htm 


\title{
Route-Based Control of Hybrid Electric Vehicles
}

\author{
Jeffrey D. Gonder \\ National Renewable Energy Laboratory
}

\begin{abstract}
Today's hybrid electric vehicle (HEV) controls do not necessarily provide maximum fuel savings over all drive cycles. An approach that employs route-based control could improve HEV efficiency at potentially minimal additional cost. This paper evaluates a range of routebased control approaches and identifies look-ahead strategies (using input from "on-the-fly" route predictions) as an area meriting further analysis. A novel implementation approach is developed and discussed, and a comparison with simulation results using an optimized general control setting indicates that fuel savings of approximately $2 \%$ to $4 \%$ can be obtained with route-based control. Given the increasing prevalence of GPS systems in vehicles, this advance has the potential to provide considerable aggregate fuel savings if applied across the entire national fleet. For instance, a $3 \%$ across-the-board reduction in HEV fuel use would save nearly 6.5 million gallons of fuel annually in the United States. These estimated savings will increase further as HEVs achieve greater market penetration.
\end{abstract}

\section{INTRODUCTION}

Interest in advanced and alternative vehicle powertrain technologies continues to grow in response to concerns about continuing increases in the cost of oil and greenhouse gas emission rates. Petroleum use in the United States also presents a security concern, since domestic production has steadily declined for decades while consumption has increased. This has forced the nation to import an ever-growing percentage-roughly $60 \%$ at present-of the oil we use [1]. Global petroleum use, particularly in the growing economies of China and India, also continues to increase at astounding rates. This has led many experts to predict that world oil production will peak within the next decade, placing great strain on the supply and demand balance in the international market [2].

Hybrid electric vehicles (HEVs) are a promising technology for reducing the amount of petroleum that vehicles consume. HEVs use an energy storage system (typically a battery pack) coupled with an electric motor to help the vehicle operate more efficiently. The alternative power path provided by the battery and motor can allow the engine to shut down when at a stop and during periods of otherwise inefficient low power operation. It also allows a smaller, more efficient engine to be used while retaining the vehicle's peak power capability. To maintain the electrical energy needed to provide these functions, the battery is recharged by accepting excess power during efficient engine operation and by recapturing kinetic energy during regenerative braking to slow down the vehicle.

In response to the driving demand, the HEV controller selects how to split the draw of energy between the battery and the engine primarily to minimize fuel consumption. (Other considerations include drive quality and emissions reduction, but these are not emphasized in the modeling discussed later in this paper.) However, this fuel minimization goal must be pursued within the constraints imposed by the vehicle's components, particularly the battery. To avoid costly battery replacements during the expected life of the vehicle, the batteries of today's commercial HEVs are restricted to a narrow region of operation, avoiding the life-reducing impacts of operating at very high and low states of charge (SOCs) and cycling between them. Reaching a defined SOC constraint (and/or related battery current and voltage limits) during the operation of the vehicle will restrict the efficiency-improvement benefit of the hybrid system. For instance, if the control strategy allows the battery to reach an upper limit on a particular cycle, the vehicle will no longer be able to capture and store regenerative braking energy. If the battery should reach a lower limit, the vehicle will no longer be able to operate in electric or electric-assist mode. These scenarios present an opportunity for a modified vehicle control strategy to use less fuel over the same cycle if it can use the hybrid functions of the vehicle in a way that avoids reaching such "hard" battery limits.

The method that an HEV controller uses to minimize operation near those hard limits presents an additional though more subtle opportunity to improve control efficiency over a particular cycle. In the absence of knowledge about upcoming driving, the controller is likely to bias the battery operation toward the midpoint SOC (between the high and low bounds). The control bias could also become stronger as the actual SOC gets farther from this target level. This situation introduces a competing input for decisions regarding drawing energy 
from the battery or the engine, and it could detract from the primary fuel minimization goal of the control strategy.

In summary, these two potential efficiency loss modes are based on adhering to the limits of the battery during unknown future driving. As a result, a fixed control strategy might not deliver minimal fuel use over all drive cycles. A control approach that instead adapts to upcoming driving could potentially improve the vehicle's efficiency at minimal cost if the only requirement is software changes. Particularly for fleet managers of predictable-route HEVs (e.g., transit buses, refuse haulers, delivery vehicles), the resulting fuel savings would directly improve their bottom line. As the increasing prevalence of Global Positioning System (GPS) devices in automobiles facilitates route prediction, those fuel savings could be spread across the entire national fleet, adding to the total reduction in petroleum use provided by HEVs.

\section{RANGE OF ADAPTIVE CONTROL APPROACHES}

This project began by examining a range of possible adaptive or route-based control approaches and identifying an area in which further work would add the most value. Figure 1 illustrates the categorization developed for the various approaches in terms of the method's ability to improve fuel efficiency and its sensitivity to a particular drive cycle.

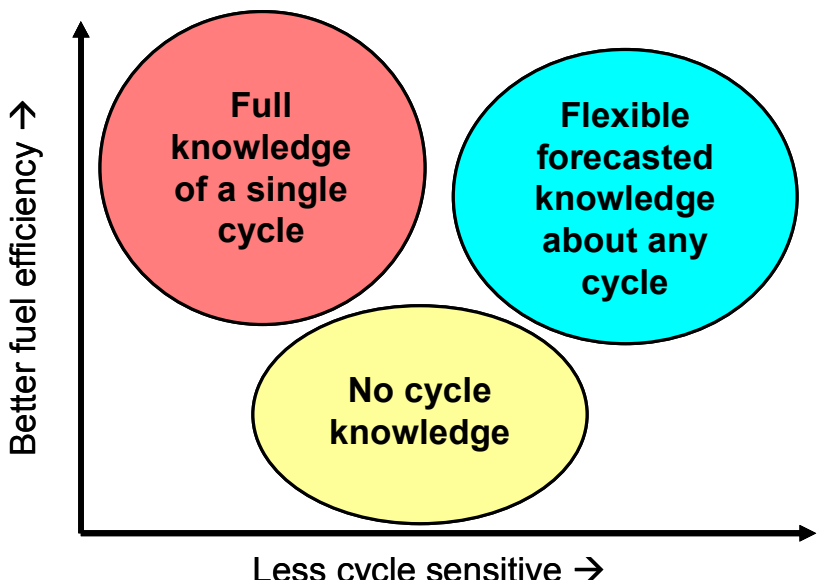

Figure 1. Categorized range of adaptive control approaches.

Any real-world control strategy must ultimately be able to fall back into the lowest category shown in Figure 1: operating with no cycle knowledge. This category includes general rule-based control strategies that rely on component maps and engineering intuition to develop control rules that are intended to maximize vehicle efficiency. Such a strategy would include rules resulting in both discharging and charging the battery; it would also contain the target SOC biasing component discussed earlier. The SOC control component causes the strategy to adapt to different cycles for which the efficiency-maximizing control rules would otherwise command continuous charging or discharging of the battery.

A slightly more sophisticated approach in the no-cycleknowledge category is local optimization, which adapts in response to instantaneous road power demands. This approach assigns a fuel replacement cost to battery energy use and selects the power split to minimize the total equivalent "cost" at each operating point $[3,4]$. However, some uncertainties exist in quantifying the replacement cost because of the unknown contribution of regenerative braking and the unknown rate of future charging that will return depleted battery energy. This requires the strategy to still use SOC control penalties to remain in the acceptable battery operating region. Note that a simple local control improvement that can be added on to any strategy is to use the instantaneous vehicle speed to predict some fraction of kinetic energy recapture from regenerative braking; this value can then be used to adjust the SOC estimate used for control biasing.

The category at the top left in Figure 1, full knowledge of a single cycle, contains options with the greatest adaptive-control fuel savings potential. However, these options have limited applicability to vehicles operating on a variety of drive cycles. Global optimization provides the ultimate level of cycle adaptation in this category by using full second-by-second a priori knowledge of the drive cycle. Unfortunately, applying a global optimization technique, such as dynamic programming, has extensive computational requirements and is unachievable in real time. Other approaches in this category tune control rules for a particular expected cycle; the results may not achieve globally optimized fuel efficiency, but the strategies can run in real-time. One such approach determines the cycle's upper bound for fuel efficiency from global optimization, and it analyzes optimized component usage results to guide rule-tuning. Another approach conducts a parametric study of different combinations of the control parameters selected for adjustment, and it identifies the tuning that optimizes fuel efficiency over the cycle. Depending on the extent of the combinations of parameters investigated, this approach can also become computationally intensive.

A number of literature examples have demonstrated fuel efficiency gains from such cycle-specific control tuning, although the magnitude of the reported benefit varies significantly [5-8]. Part of the reason for this variation is that route-based control improvements are compared against results using control settings developed from engineering intuition, rather than a rigorous process to determine optimum, all-purpose control tuning. One study compared the impact of optimizing controls and components for a given cycle and then running on several others; the study found that the vehicle optimized for the New European Drive Cycle (NEDC) had the next lowest fuel consumption on every other cycle (behind the result for that cycle's optimized vehicle) [9]. This suggests that optimizing for the NEDC may provide a 
good all-purpose tuning for making baseline comparisons.

The approaches in the last adaptive control category in Figure 1 may achieve fuel efficiency levels close to those from cycle-specific optimization, but they enjoy much less cycle sensitivity by simply relying on flexible forecasted knowledge about any upcoming cycle. One identified approach subcategory uses off-line, cyclespecific optimization over representative driving patterns to determine a set of vehicle control options. During driving, the vehicle then observes the driving pattern just completed and applies optimized controls for that type of driving to a subsequent window of operation (implicitly assuming that the same type of driving will continue). Another approach subcategory relies on repeated cycle learning to tune control parameters. Literature examples of the first approach subcategory show modest improvements with route-based control that are limited in part by the fact that past operation does not always correctly indicate the upcoming driving type $[10,11]$. The second approach subcategory suggests greater fuel efficiency gains but entails increased cycle sensitivity by requiring several sequential repetitions of the same driving pattern to achieve control parameter learning [12].

The last subcategory, identified as the look-ahead approach, might avoid the limitations of the other two by forecasting the cycle based on route predictions (such as from a GPS navigation system) rather than past driving. The approach begins with a route-independent baseline control construct, which is then modified using input from the route prediction. These inputs could include projections on road grade, stops, speed limits, and possibly traffic flow information from an Intelligent Transportation System (ITS) network. Few literature examples seem to have explored this approach; those that have suggest interesting strategies for using essentially real-time cycle prediction to make routebased control adjustments [13, 14]. Even so, ample opportunities exist for further refinements of this subcategory, which seems to provide the best trade-off between route-based efficiency improvements and reduced cycle sensitivity. In addition, more rigor is needed to establish sound baselines against which to measure route-based improvements. (One of the literature examples uses a completely different control construct for the baseline vs. route-based approach). The following sections describe the implementation of a novel look-ahead approach intended to further the body of knowledge in this area.

\section{MODEL AND METHODOLOGY DESCRIPTION}

Vehicle simulations for this work used a forward-facing modeling tool with an established rule-based HEV control strategy $[15,16]$. This selection provides the closest possible analytical examination of the impact that the proposed route-based control implementation could have on an existing HEV. The particular HEV examined used a $1540 \mathrm{~kg}$ midsize car platform with a pretransmission parallel hybrid configuration. The vehicle had a $90-\mathrm{kW}$ gasoline engine, a $30-\mathrm{kW}$ electric motor, and a battery with roughly $320 \mathrm{Wh}$ of usable energy.

The selected route-based control methodology drew on different aspects of a few of the varied approaches discussed in the previous section. Like the subcategory that optimized control settings for different representative driving patterns, this approach relies on time-intensive, off-line simulation over different driving types. However, for each driving type, this approach stores fuel and net battery energy use predictions that correspond to many different control tunings. Also, rather than relying on a past window of operation to predict the upcoming representative driving pattern, the methodology relies on GPS look-ahead forecasting to predict the upcoming cycle and then divide it into segments of different driving types. Combining a real-time segmented cycle prediction with off-line simulation results makes it possible to quickly identify the segment-by-segment control sequence leading to charge-sustaining (CS) operation and minimized fuel consumption.

As discussed earlier, the validity of any fuel savings claimed for a route-based control approach depends on how it compares with baseline control settings that have been thoroughly optimized for general driving. Therefore, the first step in this study was to identify control settings that minimize fuel consumption on the NEDC cycle, which has been shown to provide a good general tuning [9]. To determine any benefit from the route-based control methodology, vehicle simulation results over the cycles examined using NEDC-tuned parameter settings were compared with results for the same cycles using variable route-based control settings. The next section illustrates the study's methodology in more detail through an example of its application to particular drive cycles.

\section{RESULTS}

\section{DETERMINING THE GENERAL BASELINE TUNING}

The NEDC cycle optimization described earlier involved tuning parameters that control the HEV's power split between engine and motor/battery operation. These power split decisions are based on the driving demand during the cycle and the instantaneous SOC of the battery pack. The particular parameters varied for this optimization included the target SOC, the nominal road power demand to trigger engine operation, the power adjustment function (based on the difference between the instantaneous and target SOC), and the SOC thresholds for requiring engine operation. More details about these parameters and the controller architecture can be found in the model's documentation [15]. A parametric study over many NEDC simulations identified the combination of parameter values to minimize fuel consumption. Because of the long computational time requirement of forward-facing models, practical time constraints limited the extent of the parametric study to examining roughly 100 different control tunings. 


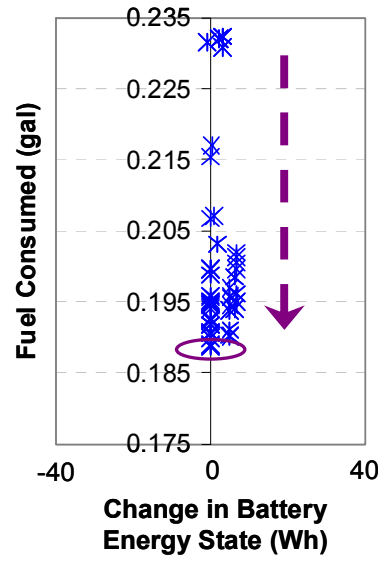

Figure 2. Parametric study simulation results over the NEDC cycle.

Figure 2 summarizes the parametric study simulation results over the NEDC cycle. Note that all of the points indicate CS results (well within the SAE J1711 recommended tolerance for stored electrical energy changing by less than $1 \%$ of the fuel energy consumed [17]). This was accomplished for each parameter case by iterating on the initial battery energy state for the cycle until it matched the state at the end of the simulation. With all CS results, the fuel consumption of all the cases can be directly compared with each other, and the general parameter tuning is the one providing the minimum fuel consumption result (circled on the figure). For this study, two cases resulted in nearly identical minimum fuel consumption, and each is considered in the next subsection as the potential general vehicle control tuning.

\section{COMPARISON OF BASELINE VS. ROUTE-BASED CONTROL OVER DIFFERENT DRIVING TYPES}

Figure 3 shows further CS simulation results for the same parametric controls study over different driving segments. The graphs highlight the comparison between results obtained using the general parameter tunings determined above and optimized results if the selected control settings were instead based on minimizing fuel consumption for the type of driving indicated. General tuning works well for many driving types, such as for the mild highway operation examined in Figure 3a with the Highway Fuel Economy Test (HWFET) cycle. However, cycle-specific control tuning does provide some benefit-roughly $1 \%$ for the HWFET case.

On the other hand, control optimization for segments of particular driving types can provide even more noticeable improvement. Figure $3 \mathrm{~b}$ presents such an example for low-speed stop-and-go driving represented by the second bag in the Urban Dynamometer Driving Schedule (UDDS). This example also exposes a difference between the two general parameter tunings identified earlier. Though both control sets produced nearly identical results for the (mixed driving type) NEDC and the HWFET cycle, they produce the outputs shown in

Figure $3 \mathrm{~b}$ as ranging from $3 \%$ to $11 \%$ worse than the fuel consumption associated with low-speed urban driving segment-optimized controls. This again demonstrates the importance of conducting a rigorous baseline control tuning. If a less extensive parametric study had identified only the first general control setting, routespecific control optimization would provide a dramatic $11 \%$ fuel savings. Even if a more extensive analysis (including the results of this example) would point to the second option identified for general parameter tuning, $3 \%$ is a significant fuel savings to achieve simply by adjusting the vehicle control settings for the particular type of driving expected. The analysis in the following subsection makes comparisons only with this second and more robust option for the general vehicle control tuning.

(a)

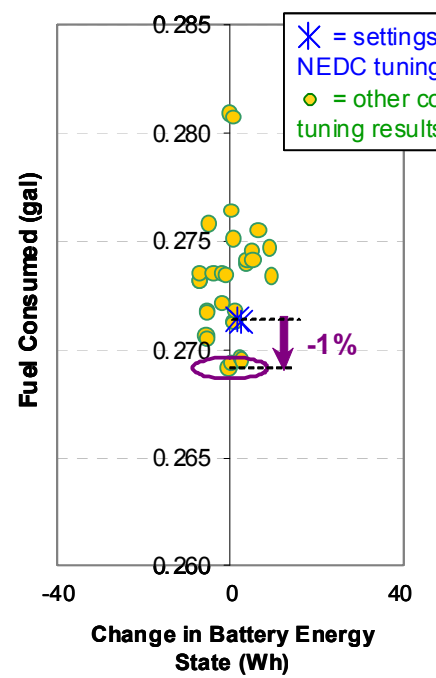

Figure 3. Parametric control tuning results over (a) the HWFET cycle and (b) bag 2 of the UDDS cycle.

\section{ROUTE-BASED CONTROL FOR CYCLES WITH SEGMENTS OF MULTIPLE DRIVING TYPES}

If an HEV were operated only over a single type of driving, the analysis described in the previous subsection would be sufficient to determine the optimal control tuning for that particular vehicle. If, however, the vehicle were operated in cycles containing multiple segments of different types of driving, this route-based control approach calls for varying the control over each driving segment. The analysis above might be insufficient for this situation, as CS operation is not necessarily achieved (or desired) over each segment of the cycle. Consider, for instance, a two-segment cycle with two different control options for the first segment-one that results in CS operation and one that consumes more fuel but also increases the energy stored in the battery. In order achieve net CS operation over the full cycle, the first segment CS control option would need to be paired with parameter settings in the second segment to again achieve CS operation. The charge-gaining control option from the first segment would need to be paired with a charge-depleting control option in the second segment to return the battery to its initial energy state. Comparing 
the two control sequence options, the fuel savings relative to the battery energy depletion for the second segment's type of driving might be greater than the additional fuel required for equivalent battery energy storage during the first segment's type of driving. For this scenario, the control sequence with non-CS individual segment operation consumes less total fuel over the full cycle.

To illustrate how to handle battery energy variation with a route-based control analysis, an examination follows of an example three-segment driving cycle, in which the segments are divided on the basis of road grade. Figure 4 illustrates the relative speeds and grades of the three roughly 6 - to 8-minute-long driving segments. The first and the third segments were collected using a GPS data logger during high-speed highway driving, first up and then back down an initial climb on Interstate 70 from Denver, Colorado, into the nearby foothills. The middle segment was taken from the high-speed portion of the Environmental Protection Agency's US06 drive cycle.

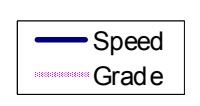

(a)

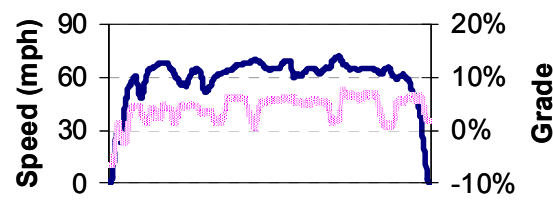

(b)

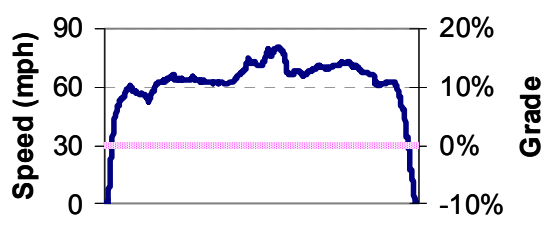

(c)

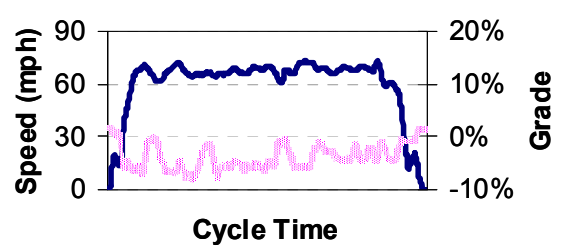

Figure 4. Relative profiles for the three-segment cycle example, composed (in order) of (a) uphill driving in foothills, (b) US06 high-speed (no grade), and (c) downhill driving in foothills.

To begin, consider an analysis similar to that for individual segment CS optimization applied to the middle segment (Figure 4b) in the example cycle. Figure 5 shows the results for conducting the parametric controls study over this cycle, but holding the initial battery energy state at a fixed value rather than iterating on it to determine a CS result. The figure shows a scattered trend for trading off battery energy vs. fuel use, and it is not as clear how to decide whether one control option is superior to another as it is in the comparison of exclusively CS results. The drawing in Figure 6a can assist the reader in understanding the process for making this determination.

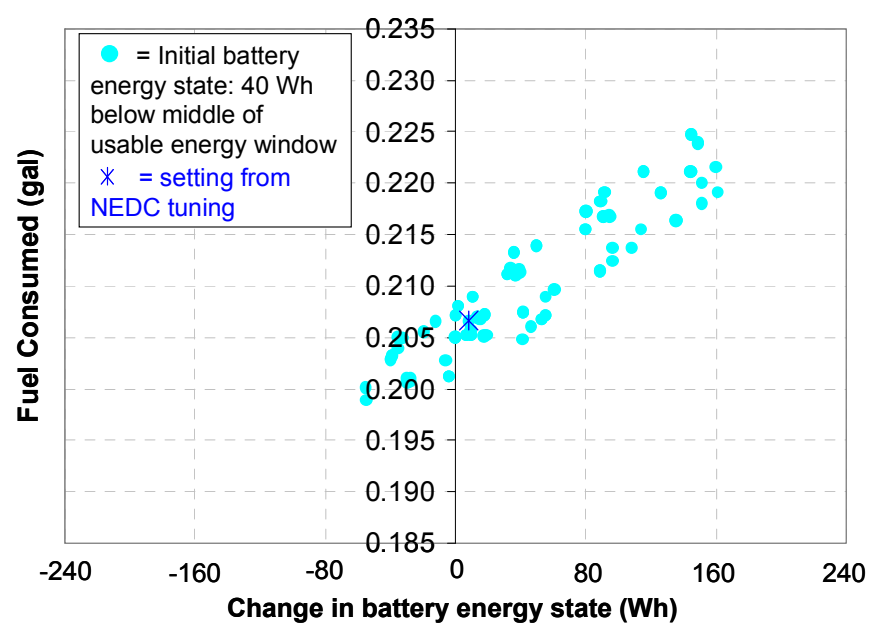

Figure 5. Simulation results over the US06 highspeed segment, all from a single initial energy state. (a)

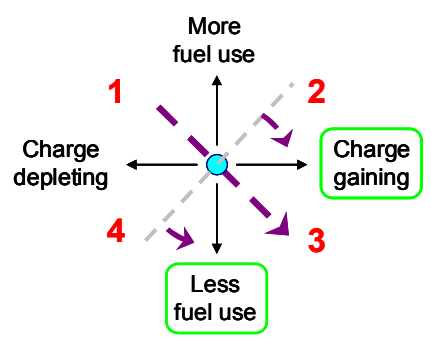

(b)

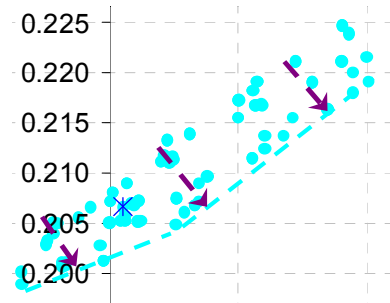

Figure 6. Illustration of the process to narrow parameter tunings considered for route-based control (axes are the same as in Figure 5).

The small circle in the middle of Figure 6a represents a hypothetical simulation result for a particular control setting. To evaluate the relative merit of a different setting that produces a result in the surrounding space, consider first the region indicated by the vertical arrows directly above and below the circle. This comparison space is analogous to the CS evaluation considered earlier: a new option resulting in the same net battery energy use is superior if it uses less fuel and inferior if it uses more fuel. A similar comparison can be made along the arrows in the horizontal direction; a new option resulting in the same total fuel consumption is superior if it adds more energy to the battery and inferior if it depletes more energy from the battery. Therefore, dividing results space into numbered quadrants, as shown in the figure, control alternatives with results falling in quadrant one would never be considered, and those with results falling in quadrant four (less fuel use and more energy stored) would always be chosen. Options with results falling in quadrants two and four can be considered, with preference given to those lying closer to the arrows pointing down or to the right. With this understanding, Figure $6 \mathrm{~b}$ indicates how consideration was narrowed from the large set of control options in Figure 5 to only those with results falling along the bottom-rightmost fuel vs. battery energy use line. 
The simulations examined in Figure 5 and Figure $6 \mathrm{~b}$ all began the driving segment at the same battery energy state ( $40 \mathrm{Wh}$ below the middle of the battery's usable energy window). Note that using the same control options with different initial energy states produces different results in terms of fuel vs. battery energy use. Figure 7 shows the simulation results for the US06 highspeed segment from Figure 5 along with results for a repeated parametric controls study using three different initial battery energy states. Applying the process described above to rank the control settings results in the narrowed options for consideration shown in Figure 8.

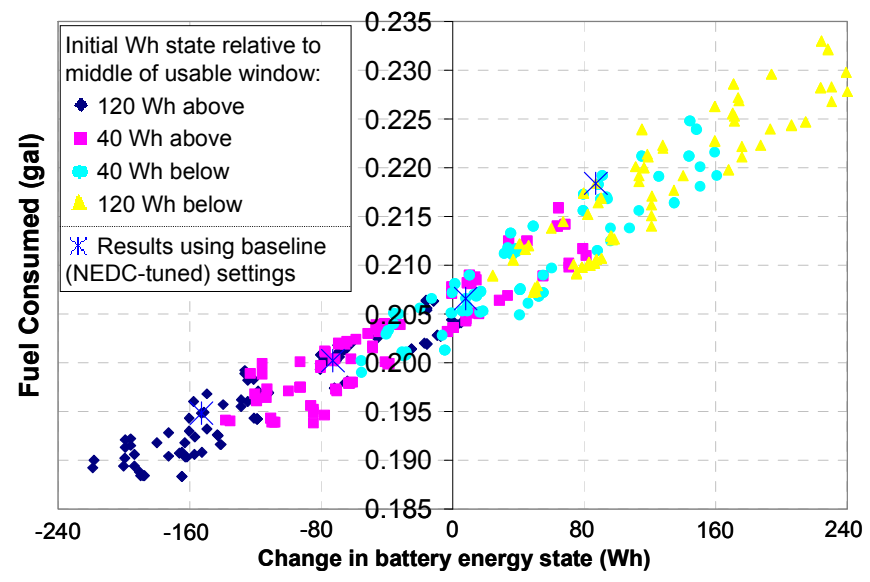

Figure 7. Simulation results over the US06 highspeed segment for different initial energy states.

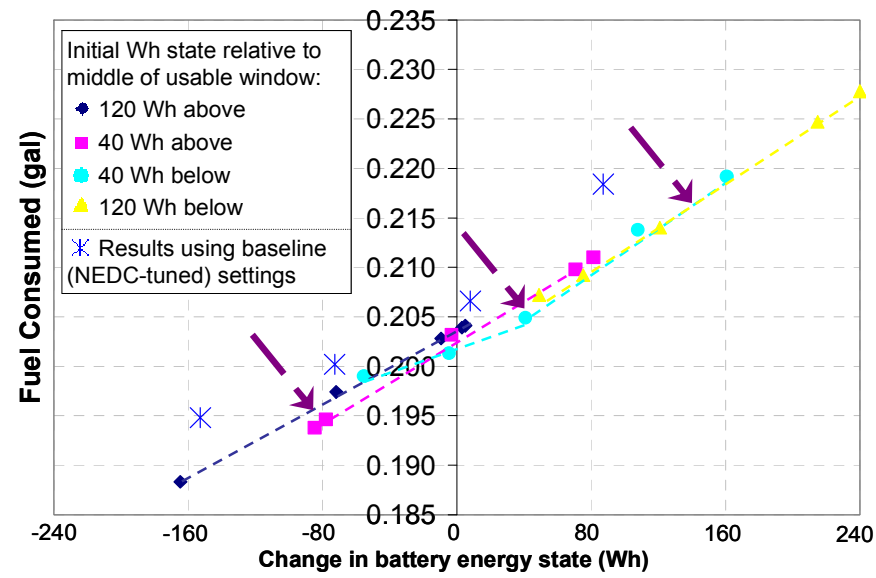

Figure 8. US06 high-speed segment results with narrowed options for route-based control.

This off-line simulation process can be repeated for other driving types, such as the uphill and downhill foothills driving segments introduced earlier. With a narrowed list of route-based control options to consider for different driving segment types (and the associated fuel vs. battery energy use results), it is possible to quickly interpolate the total fuel and battery energy estimates for each combination of segment controls over a particular multi-segment cycle prediction. The route-based controller would then select the combination providing the lowest fuel use. Simulating the example cycle with a fuel-minimized variable segment control sequence confirms the fuel savings relative to the simulation result using constant general control settings. Figure 9 shows the $2 \%$ fuel savings observed both for the CS full-cycle simulation comparison and across the range of non-CS full-cycle comparisons.

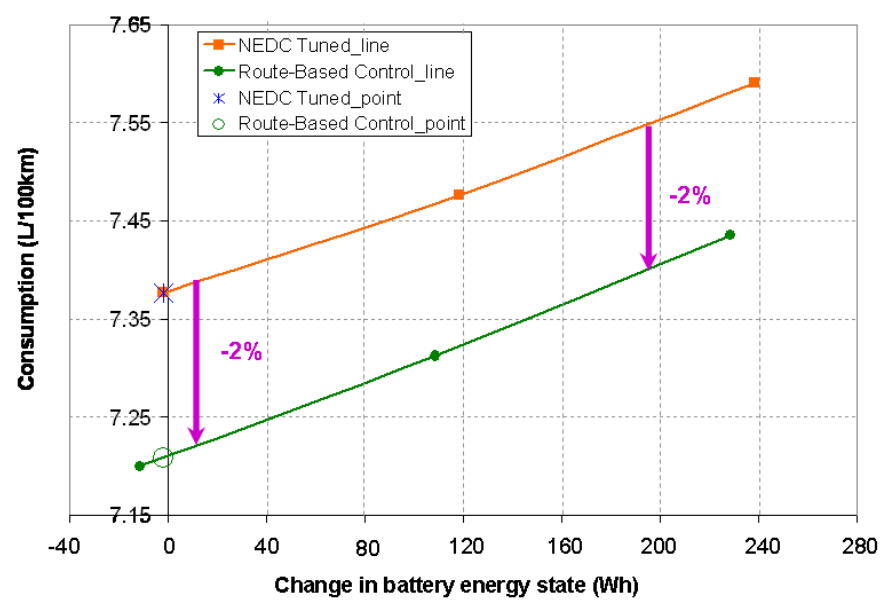

Figure 9. Fuel savings resulting from route-based control over the full multisegment cycle.

\section{SUMMARY OF RESULTS AND OBSERVATIONS}

Information on battery usage is included in the summary table below to capture some of the impact route-based control may be having beyond fuel savings. The drawing in Figure 10 illustrates how the summary battery energy window metric was determined. The drawing indicates how the battery energy state oscillates through the course of a drive cycle, decreasing when supplying energy for electric assistance and increasing when capturing energy from engine load leveling or regenerative braking. For consistent comparisons of CS results, the profile for each case will return to the initial energy state. But the energy window defined by the difference between the maximum and minimum energy locations may differ. Interest in this metric stems from the fact that expanded cycling may shorten battery life.

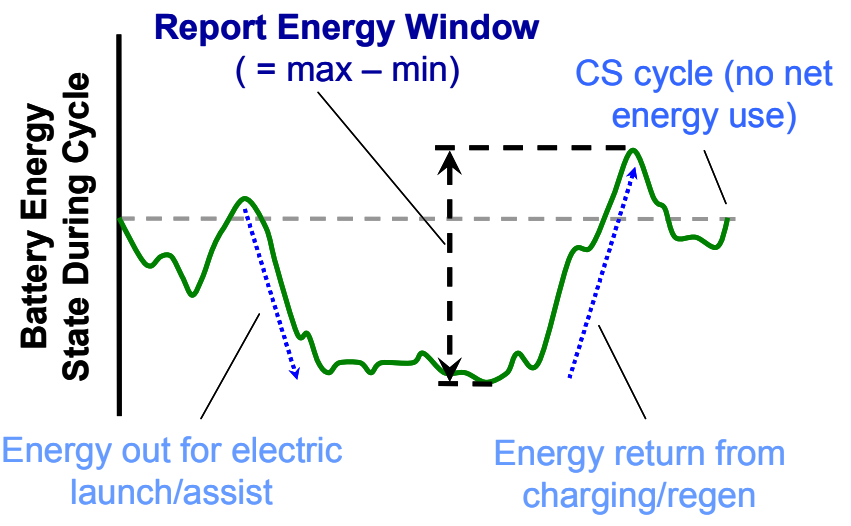

Figure 10. Example of a battery energy use profile for a particular cycle/control combination.

The UDDS Bag 2 comparisons summarized in Table 1 show that route-based control can provide a sizable benefit for specific expected driving types, but that fuel savings depend on the robustness of the general/baseline parameter tuning selected. With respect to battery use, both UDDS Bag 2 comparisons show a considerable increase in the energy window used 
with the route-optimized scenario. This presents a potential concern if the route-based solution is achieving fuel savings at the expense of battery life. However, the total energy window for this example remains a fraction of the permissible operation region, defined by the roughly $320-\mathrm{Wh}$ usable window for this vehicle.

Table 1. Summary comparisons of route-based control (RBC) to general baseline tuning results

\begin{tabular}{|c|c|c|c|}
\hline Cycle & $\underline{\text { Comparison }}$ & $\underline{\text { Suvings }}$ & $\begin{array}{l}\frac{\text { Change }}{\text { in Wh }} \\
\underline{\text { Window }}\end{array}$ \\
\hline \multirow{2}{*}{$\begin{array}{l}\text { UDDS Bag } 2 \\
\text { Segment } \\
\text { (low-speed } \\
\text { stop and go) }\end{array}$} & $\begin{array}{l}\text { RBC vs. General } \\
\text { (initial) }\end{array}$ & $10.6 \%$ & $\begin{array}{c}66 \rightarrow \\
151 \mathrm{Wh}\end{array}$ \\
\hline & $\begin{array}{l}\text { RBC vs. General } \\
\text { (revised) }\end{array}$ & $2.8 \%$ & $\begin{array}{l}86 \rightarrow \\
151 \mathrm{Wh}\end{array}$ \\
\hline $\begin{array}{c}\text { Foothills } \\
\text { grades + US06 } \\
\text { high speed }\end{array}$ & $\begin{array}{l}\text { RBC vs. General } \\
\text { (revised) }\end{array}$ & $2.3 \%$ & $\begin{array}{l}321 \rightarrow \\
270 \mathrm{Wh}\end{array}$ \\
\hline $\begin{array}{c}\text { Foothills + } \\
\text { HWFET (mis- } \\
\text { prediction) }\end{array}$ & $\begin{array}{c}\text { Same RBC vs. } \\
\text { General }\end{array}$ & $0.4 \%$ & $\begin{array}{l}306 \rightarrow \\
275 \mathrm{Wh}\end{array}$ \\
\hline
\end{tabular}

Table 1 also summarizes the route-based control fuel savings from the multisegment cycle example. In this case, the battery energy window actually decreases by about $50 \mathrm{Wh}$ (from occupying the full usable window) with the route-based control solution. This suggests that achieving control-based fuel savings and life-extending battery use changes may not be mutually exclusive. The last row in the table summarizes a brief investigation of the impact from mispredicting the upcoming cycle when determining the route-based control sequence. For the case shown, the foothills grades with US06 high-speed three-segment cycle dictates the control sequencing, but in the actual tested cycle the US06 high-speed segment is replaced by the HWFET (lower speed, less aggressive highway driving). Even with this deficiency, the routebased control approach achieves a result at least as good if not slightly better than the general/baseline tuning result over the same cycle, both with respect to fuel savings and battery energy window use.

\section{CONCLUSION}

This paper discusses the spectrum of possible routebased control approaches and highlights the importance of establishing a sound baseline strategy against which to evaluate the route-based improvement. A detailed look-ahead control implementation is also discussed, and comparisons are made with fixed control using a general parameter tuning. The example implementation demonstrates fuel savings that are approximately $2 \%$ to $4 \%$ better than results for static general tuning. These savings are moderated by practical considerations (e.g., computational time, cycle flexibility, and building on an existing HEV control architecture), but they could be considerable in aggregate if applied across an entire fleet of vehicles. For instance, based on an estimate of total U.S. HEV fuel consumption in 2006 [18], an aggressive 3\% across-the-board reduction in HEV fuel use would save nearly 6.5 million gallons of fuel annually, an estimate that will increase with greater HEV market penetration. Alternative approaches to achieving comparable fuel savings, such as through the use of exotic lightweight materials or advanced component replacements, often carry a recurring vehicle cost premium. By requiring only software changes, the implementation of route-based control could prove to be more cost effective. Route-based control does have the potential to impact the way in which a hybrid system uses its vehicle's battery, so additional care must be taken to ensure that overall battery impacts are neutral or beneficial (rather than detrimental).

A logical next step for this work is to collaborate in demonstrating actual route-based control fuel savings in a research partner's HEV platform. Other possible areas include exploring the logistics of translating GPS map routes into representative driving cycle predictions and further investigating the results' sensitivity to variations in the representative cycle. The approach might also be applied next to achieving additional fuel savings in a plug-in hybrid electric vehicle (PHEV) and to pursue other HEV/PHEV benefits, such as extending battery life or reducing vehicle emissions.

\section{ACKNOWLEDGMENTS}

The author would like to acknowledge the programmatic support of the U.S. Department of Energy (DOE) Office of Energy Efficiency and Renewable Energy FreedomCAR and Vehicle Technologies Program.

\section{REFERENCES}

1. U.S. Energy Information Administration, www.eia.doe.gov. Accessed September 11, 2007.

2. Hirsch, R., Bezdek, R., and Wendling, R. "Peaking of World Oil Production: Impacts, Risks, and Mitigation." U.S. Department of Energy, February 2005. Available online at www.netl.doe.gov/energyanalyses/pubs/Oil Peaking NETL.pdf.

3. Johnson, V.H., et al. "HEV Control Strategy for RealTime Optimization of Fuel Economy and Emissions." SAE, 2000.

4. Jeanneret, B., and Markel, T. "Adaptive Energy Management Strategy for FCHV's." SAE, 2004.

5. Tate, E., and Boyd, S. "Finding the Ultimate Limits of Performance for Hybrid Electric Vehicles." SAE, 2000.

6. Lin, C.-C., et al. "Energy Management Strategy for a Parallel Hybrid Electric Truck." American Control Conference, 2001.

7. Lin, C.-C., et al. "Control System Development for an Advanced-Technology Medium-Duty Hybrid Electric Truck." SAE, 2003.

8. Pagerit, S., et al. "Global Optimization to Real Time Control of HEV Power Flow: Example of a FCHEV." EVS21, 2005. 
9. Wipke, K., Markel, T., and Nelson, D. "Optimization of Energy Management Strategy and Degree of Hybridization for a Hydrogen Fuel Cell SUV." EVS 18, 2001.

10. Jeon, S., et al. "Adaptive Multi-Mode Control Strategy for a Parallel HEV based on Driving Pattern Recognition." ASME IMECE, 2003.

11. Lin, C.-C., et al. "Driving Pattern Recognition for Control of Hybrid Electric Trucks." Vehicle System Dynamics, Vol. 42, Nos. 1-2, pp. 41-58, 2004.

12. Chen, J.-S., and Salman, M. "Learning Energy Management Strategy for Hybrid Electric Vehicles." IEEE, 2005.

13. Rajagopalan, A., and Washington, G. "Intelligent Control of Hybrid Electric Vehicles Using GPS Information." SAE, 2002.

14. Deguchi, Y., et al. "HEV Charge/Discharge Control System Based on Navigation Information." SAE, 2004.

15. Argonne National Laboratory, PSAT (Powertrain Systems Analysis Toolkit). Available online at www.transportation.anl.gov/.

16. Rousseau, A., Sharer, P., and Besnier, F. "Feasibility of Reusable Vehicle Modeling: Application to Hybrid Vehicles." SAE paper 2004-01-1618, SAE World Congress, Detroit, March 2004.

17. "Society of Automotive Engineers Surface Vehicle Recommended Practice J1711, Recommended Practice for Measuring Fuel Economy of HybridElectric Vehicles." SAE, March 1999.

18. Bennion, K., and Thornton, M. "Hybrid Electric Vehicle Fuel Savings." NREL Technical Report (forthcoming).

\section{CONTACT}

Jeffrey Gonder, Research Engineer at the National Renewable Energy Laboratory (NREL) (jeff_gonder@nrel.gov), joined NREL's Center for Transportation Technologies and Systems (CTTS) in 2005. His areas of research include investigating designs and control strategies for hybrid, plug-in hybrid, and fuel cell vehicles. He is also involved in the testing and analysis of energy storage devices for advanced vehicles. Before coming to NREL, he developed fuel cell systems and helped to lead the design and construction of a plug-in hybrid fuel cell vehicle at Anuvu Inc. in Sacramento, California. He holds a B.S. in Mechanical Engineering from the University of Colorado and an M.S. in Mechanical Engineering from Penn State University, where he also participated in DOE-sponsored hybrid electric vehicle competitions. 


\section{REPORT DOCUMENTATION PAGE}

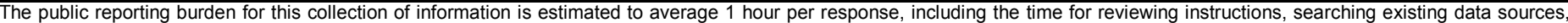

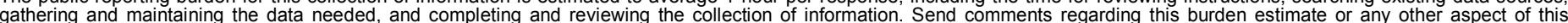

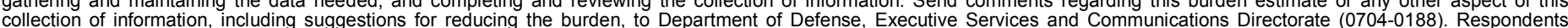

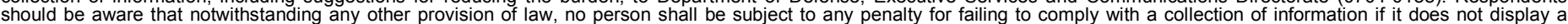

should be aware that notwithstandin

PLEASE DO NOT RETURN YOUR FORM TO THE ABOVE ORGANIZATION.

\begin{tabular}{l|l|l|l} 
1. REPORT DATE $(D D-M M-Y Y Y Y)$ & 2. & REPORT TYPE & 3. DATES COVERED (FrOm - TO)
\end{tabular}

January 2008

Conference Paper

4. TITLE AND SUBTITLE

Route-Based Control of Hybrid Electric Vehicles: Preprint

5a. CONTRACT NUMBER

DE-AC36-99-G010337

5b. GRANT NUMBER

5c. PROGRAM ELEMENT NUMBER

6. AUTHOR(S)

J.D. Gonder

5d. PROJECT NUMBER

NREL/CP-540-42557

5e. TASK NUMBER

FC082000

5f. WORK UNIT NUMBER
7. PERFORMING ORGANIZATION NAME(S) AND ADDRESS(ES)

National Renewable Energy Laboratory

1617 Cole Blvd.

Golden, CO 80401-3393
8. PERFORMING ORGANIZATION REPORT NUMBER

NREL/CP-540-42557

9. SPONSORING/MONITORING AGENCY NAME(S) AND ADDRESS(ES)

10. SPONSOR/MONITOR'S ACRONYM(S) NREL

11. SPONSORING/MONITORING AGENCY REPORT NUMBER

12. DISTRIBUTION AVAILABILITY STATEMENT

National Technical Information Service

U.S. Department of Commerce

5285 Port Royal Road

Springfield, VA 22161

13. SUPPLEMENTARY NOTES

14. ABSTRACT (Maximum 200 Words)

Today's hybrid electric vehicle (HEV) controls do not necessarily provide maximum fuel savings over all drive cycles. A route-based control approach employing vehicle GPS technology could improve HEV efficiency at little additional cost. This paper evaluates a range of route-based control approaches and identifies strategies meriting further analysis. Results indicate that fuel savings of $2 \%$ to $4 \%$ can be obtained with route-based control. Given the prevalence of GPS systems, savings could be significant if this approach is applied across the entire national fleet. For example, a 3\% across-the-board reduction in HEV fuel use could save nearly 6.5 million gallons of fuel annually.

\section{SUBJECT TERMS}

hybrid electric vehicles; HEV; HEV fuel savings; HEV controls; route-based control

\begin{tabular}{|c|c|c|}
\hline $\begin{array}{l}\text { a. REPORT } \\
\text { Unclassified }\end{array}$ & $\begin{array}{l}\text { b. ABSTRACT } \\
\text { Unclassified }\end{array}$ & $\begin{array}{l}\text { c. THIS PAGE } \\
\text { Unclassified }\end{array}$ \\
\hline
\end{tabular}

\begin{tabular}{|c|c|}
\hline $\begin{array}{l}\text { 17. LIMITATION } \\
\text { OF ABSTRACT }\end{array}$ & $\begin{array}{l}\text { 18. NUMBER } \\
\text { OF PAGES }\end{array}$ \\
\hline UL & \\
\hline
\end{tabular}

19a. NAME OF RESPONSIBLE PERSON

19b. TELEPHONE NUMBER (Include area code) 